\title{
Reliability and heterogeneity of railway services
}

Michiel J.C.M. Vromans, Rommert Dekker, and Leo G. Kroon

\begin{tabular}{|l|l|}
\hline \multicolumn{2}{|l|}{ ERIM REPORT SERIES RESEARCH IN MANAGEMENT } \\
\hline ERIM Report Series reference number & ERS-2003-090-LIS \\
\hline Publication & 2003 \\
\hline Number of pages & 23 \\
\hline Email address corresponding author & mvromans@fbk.eur.nl \\
\hline Address & Erasmus Research Institute of Management (ERIM) \\
& Rotterdam School of Management / Faculteit Bedrijfskunde \\
& Rotterdam School of Economics / Faculteit \\
& Economische Wetenschappen \\
& Erasmus Universiteit Rotterdam \\
& P.O. Box 1738 \\
& 3000 DR Rotterdam, The Netherlands \\
& Phone: +31 10 408 1182 \\
& Fax: +31 10 408 9640 \\
& Email: info@erim.eur.nl \\
& Internet: www.erim.eur.nl \\
\hline
\end{tabular}

Bibliographic data and classifications of all the ERIM reports are also available on the ERIM website: www.erim.eur.nl 


\title{
ERASMUS RESEARCH INSTITUTE OF MANAGEMENT
}

\author{
REPORT SERIES \\ RESEARCH IN MANAGEMENT
}

\begin{tabular}{|c|c|c|}
\hline \multicolumn{3}{|c|}{ BIBLIOGRAPHIC DATA AND CLASSIFICATIONS } \\
\hline Abstract & \multicolumn{2}{|c|}{$\begin{array}{l}\text { Reliability is one of the key factors in transportation, both for passengers and for cargo. This } \\
\text { paper examines reliability in public railway systems. Reliability of railway services is a complex } \\
\text { matter, since there are many causes for disruptions and at least as many causes for delays to } \\
\text { spread around in space and time. One way to increase the reliability is to reduce the propagation } \\
\text { of delays due to the interdependencies between trains. In this paper we attempt to decrease } \\
\text { these interdependencies by reducing the running time differences per track section, i.e. by } \\
\text { creating more homogeneous timetables. Because of the complexity of railway systems, we use } \\
\text { network wide simulation for the analysis of the alternative timetables. We report on both } \\
\text { theoretical and practical cases. Besides a comparison of different timetables, also general } \\
\text { timetabling principles are deduced. }\end{array}$} \\
\hline \multirow{3}{*}{$\begin{array}{l}\text { Library of Congress } \\
\text { Classification } \\
\text { (LCC) }\end{array}$} & $5001-6182$ & Business \\
\hline & $5201-5982$ & Business Science \\
\hline & HD 9712 & Railroad rolling stock \\
\hline \multirow{3}{*}{$\begin{array}{l}\text { Journal of Economic } \\
\text { Literature } \\
\text { (JEL) }\end{array}$} & M & Business Administration and Business Economics \\
\hline & $\begin{array}{l}\text { M } 11 \\
\text { R } 4\end{array}$ & $\begin{array}{l}\text { Production Management } \\
\text { Transportation Systems }\end{array}$ \\
\hline & L 92 & Railroads ... \\
\hline \multirow{3}{*}{$\begin{array}{l}\text { European Business Schools } \\
\text { Library Group } \\
\text { (EBSLG) }\end{array}$} & $85 \mathrm{~A}$ & Business General \\
\hline & $\begin{array}{l}260 \mathrm{~K} \\
240 \mathrm{~B}\end{array}$ & $\begin{array}{l}\text { Logistics } \\
\text { Information Systems Management }\end{array}$ \\
\hline & $260 \mathrm{Q}$ & Transportation \\
\hline \multicolumn{3}{|c|}{ Gemeenschappelijke Onderwerpsontsluiting (GOO) } \\
\hline \multirow[t]{3}{*}{ Classification GOO } & 85.00 & Bedrijfskunde, Organisatiekunde: algemeen \\
\hline & $\begin{array}{l}85.34 \\
85.20\end{array}$ & $\begin{array}{l}\text { Logistiek management } \\
\text { Bestuurlijke informatie, informatieverzorging }\end{array}$ \\
\hline & 85.03 & Methoden en technieken, operations research \\
\hline \multirow[t]{3}{*}{ Keywords GOO } & \multicolumn{2}{|c|}{ Bedrijfskunde / Bedrijfseconomie } \\
\hline & \multicolumn{2}{|c|}{ Bedrijfsprocessen, logistiek, management informatiesystemen } \\
\hline & \multicolumn{2}{|c|}{ Spoorwegvervoer, betrouwbaarheid, dienstregeling, simulatiemodellen } \\
\hline Free keywords & \multicolumn{2}{|c|}{ Railways, transportation, reliability, heterogeneity, simulation } \\
\hline
\end{tabular}




\title{
Reliability and heterogeneity of railway services
}

\author{
Michiel J.C.M. Vromans ${ }^{\mathrm{a}}$, Rommert Dekker ${ }^{\mathrm{b}}$, and Leo G. Kroon ${ }^{\mathrm{a}, \mathrm{c}}$ \\ ${ }^{a}$ Department of decision and information management, \\ School of Management, Erasmus University Rotterdam, the Netherlands \\ ${ }^{\mathrm{b}}$ Department of econometrics and operations research, \\ School of Economics, Erasmus University Rotterdam, the Netherlands \\ ${ }^{\mathrm{c}}$ Logistics department, Netherlands Railways, Utrecht, the Netherlands
}

\begin{abstract}
Reliability is one of the key factors in transportation, both for passengers and for cargo. This paper examines reliability in public railway systems. Reliability of railway services is a complex matter, since there are many causes for disruptions and at least as many causes for delays to spread around in space and time.

One way to increase the reliability is to reduce the propagation of delays due to the interdependencies between trains. In this paper we attempt to decrease these interdependencies by reducing the running time differences per track section, i.e. by creating more homogeneous timetables.

Because of the complexity of railway systems, we use network wide simulation for the analysis of the alternative timetables. We report on both theoretical and practical cases. Besides a comparison of different timetables, also general timetabling principles are deduced.
\end{abstract}

Keywords: railways, transportation, reliability, heterogeneity, simulation

\section{Introduction}

Railway infrastructure capacity is limited and has therefore to be used carefully. Due to the increased utilization of the railway infrastructure in the Netherlands over the past years, the railway system has become quite vulnerable to disruptions. This resulted in a lower punctuality and in many customer complaints.

In the Netherlands, the railway system is characterized by many interconnected relations. Passenger transfers, rolling stock circulations and crew schedules all play their role in the relations between trains. However, the shared use of the same infrastructure by different railway services, with different origins and destinations, different speeds, and different halting patterns, is probably the main reason for the propagation of delays throughout the network. This makes such a national railway system much more vulnerable to disruptions than metro systems.

Reliability is, together with door-to-door travel time, one of the predominant performance measures in railway traffic. The predictability of the arrival times is a big factor in deciding to use rail or road transport, both for passengers and for cargo.

In this paper we investigate the effect of the heterogeneity of the timetable on the reliability of the railway system. This is a subject on which a lot of practical intuition exists, but hardly any scientific literature can be found. Railway traffic is considered 
to be heterogeneous when trains have large running time differences on the same track sections. When running times per track section are more or less equal for all trains, then the timetable is called homogeneous. The research goal of this paper implies that we are mainly interested in relatively small initial (primary) disturbances, because no reasonable timetable is robust enough to handle large disturbances or disruptions without severe on-line adjustments of the railway traffic.

Many characteristics and details of a railway timetable have their influence on the reliability. Therefore, to understand the relations properly, one first needs to know how a timetable is constructed. Starting from the market demand, line planning is the first phase in railway planning, where train connections are determined: starting and ending stations of lines are chosen, including the routes, and the stations at which has to be stopped for alighting and boarding. The chosen lines determine the service differentiation -intercity trains, local trains, cargo, etc.- and consequently a large part of the heterogeneity of the timetable. The line planning step is followed by the timetabling step, where departure and arrival times are chosen. There are often several iterations between these two steps, because a preferred line plan does not imply a feasible timetable. Feedback loops may have to be executed.

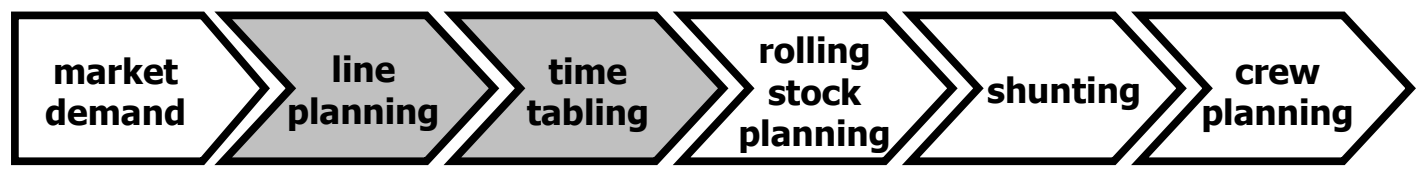

Figure 1: Sequence of interdependent railway planning phases

When the timetable is finished, the rolling stock circulation is planned. This step also includes shunting and scheduling repositioning trips. Both for the regular trains and for the shunting work, train drivers have to be scheduled. For passenger trains, also conductors are needed. Although the steps presented in the flow-diagram above depend on each other in the presented order, coordination between these steps is not easy. This means that not all the forward consequences of a certain planning step are taken into account immediately. For example, in the timetabling phase, one cannot always foresee the resulting impact on the rolling stock circulations nor the impact on the crew schedules. Again, feedback loops may be necessary.

The line plan and the timetable determine the heterogeneity of the railway system to a large extent. Since we investigate the influence of the heterogeneity on the reliability and the punctuality, we focus on the line planning and the timetabling steps.

In this paper we develop timetables which mainly differ from each other in heterogeneity. While keeping the numbers of stops per hour equal for all stations, we develop more heterogeneous and more homogeneous timetables both for a theoretical case and for a practical case.

To quantify the differences between these timetables, two new heterogeneity measures are proposed. These new measures follow the ideas described by Carey (Carey, 1999), but they also take into account several other characteristics of the timetable. These two new heterogeneity measures are not only used for the evaluation of the timetables, but also for the prediction of the reliability.

In this paper, detailed simulation of the railway systems is used for the comparison of the heterogeneous and the homogeneous timetables. A wide range of disturbance distributions and disturbance levels is used for this evaluation. 
Because cargo trains cover less than ten percent of the Dutch railway traffic, we concentrate on passenger trains in this paper. Furthermore, we assume, as is common in several European countries, that the timetables are cyclic. This means that passenger services are repeated every cycle time, typically every hour.

When researching heterogeneity, double track sections are more relevant than single track sections or sections with four parallel tracks. Indeed, the timetable for singletrack lines is mostly dictated by the distances between passing points. In the case of four parallel tracks, trains with different speeds are usually already separated, and each track has its own speed: one track for slow traffic, and one for fast traffic. The interesting part is where all trains for one direction run on one track: double track lines. Notice that many of Europe's main lines are, at least, double track lines indeed.

This paper starts with an introduction on railway reliability, including a literature overview. This is followed in section 3 by a discussion on heterogeneity and its influence on reliability. Also the new heterogeneity measures are introduced here. Sections 4 and 5 present a theoretical and a practical case, respectively. The principle of homogenization is further discussed in section 6. Conclusions follow in section 7.

\section{Punctuality and Reliability}

When investigating railway reliability, it is important to make a distinction between primary and secondary delays. Primary delays are initial delays caused on a train from the outside and not by other trains. These delays are caused by malfunctioning rolling stock, malfunctioning infrastructure, bad weather conditions, excessive alighting and boarding times of passengers, accidents at road-railroad crossings, and so on. Secondary delays are those delays of trains that are caused by earlier delays of other trains. They are also referred to as knock-on delays. Secondary delays appear because of the shared use of the same infrastructure, rolling stock connections, transfers in crew schedules, passenger transfers, dispatching actions, and so on. In our study we consider the primary delays as given, and we aim at developing timetables which both absorb primary delays fast and cause as few secondary delays as possible.

The measures which are chosen for evaluating the reliability are the average delays and the observed punctuality. Punctuality is probably the most widely used reliability measure in practice (Schaafsma, 2001), both in the Netherlands and abroad. This measure calculates the percentage of trains arriving within a certain number of minutes from the scheduled arrival time. In practice in the Netherlands, a three-minute margin is used. However, in most other countries -as well as for international comparisons- a five minute margin is more common.

Besides the arrival punctuality, also the departure or the start-up punctuality can be calculated. Furthermore, it is important at which stations the punctuality is measured.

In simulation research, it is quite easy to compare punctualities on different punctuality margins and on different sets of stations, train types or lines. Other possible measures for reliability, which are not considered in this paper, are the percentage of realized passenger transfers and the average delays of the passengers. 


\section{Literature overview}

Over the last fifteen years, a wide range of researchers has studied railway timetabling and punctuality issues. Literature reports on different types of timetable evaluation models. In the following, we first describe the analytical delay models, starting with max-plus algebra. Thereafter, stochastic models are described, and finally the focus is on railway simulation.

Max-plus algebra is an analytical approach for evaluating the robustness of a timebable. Some relevant key characteristics, such as the minimum cycle time, can be calculated with max-plus algebra (Subiono, 2000; Goverde and Soto y Koelemeijer, 2000; Van Egmond, 2000; De Kort, 2000). PETER, an analysis tool based on maxplus algebra, is a performance evaluator for timetables (Soto y Koelemeijer et al., 2000; Goverde and Odijk, 2002). Whereas max-plus algebra cannot handle stochastic elements, Hansen (2000) uses both queuing theory and max-plus algebra to study the capacity and stability of railway systems, but only in stations.

Huisman, Boucherie and Van Dijk developed a stochastic analytical waiting line model for analyzing delays at a double track section (Huisman and Boucherie, 2001; Huisman et al., 2002). Their models are based on train frequencies and running times only, not on detailed timetables with arrival and departure times.

Higgins, Kozan and Ferreira come up with a model to quantify the risk of delays on a single track line (Higgins et al., 1995). Higgins and Kozan also developed an analytical model to quantify the expected delays of individual passenger trains in an urban rail network (Higgins and Kozan, 1998).

Carey and Kwiecinski (1995) mainly focus on recovery times in their stochastic analysis. Carey also uses heuristic measures for timetable reliability (Carey, 1999) and includes behavioral response (Carey, 1998). These approaches are rather simplified, and they lack verification with reality.

Other researchers use simulation as a tool to analyze the influence of delays on the train circulation, given some traffic scenario. SIMON is a Swedish software tool using simulation of the whole network (Wahlborg, 1996; Bergmark, 1996). Amongst others, VirtuOS (König, 2001) and SABINE (Fischer et al., 1995) are used in Germany, and Open Track (Hürlimann, 2001) is a railway simulation program developed at ETH Zürich. UX-SIMU is used for simulation of railway traffic in Denmark (Kaas, 2000).

This literature is mainly focused on the simulation software itself and sometimes on a simple comparison of multiple timetables. More thorough research of the impact of timetabling principles on the corresponding reliability is hardly found.

However, Middelkoop and Bouwman describe the use of SIMONE (Middelkoop and Bouwman, 2000, 2001) for the evaluation of traffic scenarios in the Netherlands. SIMONE is capable of simulating the entire Dutch railway network. In this paper we also use SIMONE to execute theoretical analyses on the basis of simulation.

\section{Homogeneity, Heterogeneity, and Headways}

Railway traffic is considered to be homogeneous if all trains have similar characteristics, especially the same average speed per track segment, resulting from the running times and the stopping times. Appropriate examples of homogeneous railway traffic are metro systems where all trains have the same running times per 
track and where all trains stop at all stations. However, for national railway networks, railway traffic cannot be fully homogeneous. Usually cargo trains and passenger trains share the same infrastructure. But probably a more important factor is the large differentiation in passenger services, ranging from short distance trains -which dwell at nearly all stations underway-, via intercity trains, to international high speed connections -with high speeds, only stopping at a few large stations-, partly sharing the same infrastructure. If there are large differences in the timetable characteristics of the trains on the same track, then the railway traffic is called heterogeneous.

\section{Possibilities for homogenization}

Homogenization of a railway system means that differences in running times per track section of different trains along a railway line are decreased. There are several alternative options for homogenization:

- Slowing down express trains: by adding extra running time supplement.

- Speeding up short distance services: by decreasing running time supplements or by using faster rolling stock.

- Overtaking: in case of overtaking, the running time differences should only be regarded between two consecutive overtaking stations.

- Shorter lines for the short distance services: the running time differences should only be regarded over the reduced length of the line.

- Equalizing the number of stops: shift some stops from the short distance services to the long distance services.

\section{Hypothesis}

When heterogeneous services share the same infrastructure over large distances, timetabling becomes very complicated. Heterogeneity usually leads to many small headway times, which may increase delay propagation in the operations. Therefore, we propose the following hypothesis, which is studied in the remainder of this paper

Hypothesis: the heterogeneity resulting from the line plan and the timetable has a negative influence on the punctuality and the reliability of a railway system.

In order to support this hypothesis, we first develop two heterogeneity measures. Then simulation of both theoretical and practical cases is used to show the importance of homogeneity of a timetable. Besides the fact that we use the heterogeneity measures in this paper for a theoretical comparison of different timetables, it is also intended to be useful for the development of timetables for real world operations.

\section{Heterogeneity measures}

Given the train frequency of a line, the average headway at a location along that line is simply equal to the cycle time divided by the frequency. More useful headway measures are described by Carey (Carey, 1999). He shows that equalizing scheduled headways for one station has a positive influence on the punctuality when train delay distributions are equal for all trains and sloping downward. The measures he describes are based on this principle. These measures include:

- the percentage of headways smaller than a certain size;

- the percentiles of the headway distribution;

- range, standard deviation, variance, or mean absolute deviation of the headways.

The further description of these measures in the mentioned paper implies that the headways are measured at one single location only. 
An important disadvantage of measuring headways at only one single location is that this does not tell anything about the behavior of the trains on the surrounding track sections. Therefore we consider the smallest headways between two consecutive trains on a certain track section instead of at one single location. When the trains on a certain track section are completely homogeneous, then the sum of the smallest headways on this track section is equal to the cycle time. On the contrary, when traffic on a certain track is highly heterogeneous, then the short distance trains depart just after the long distance trains at the start of the track section, and the long distance trains arrive just after the short distance trains at the end of the track section. This leads to a small total sum of smallest headways.

The disadvantage of just taking the sum of the smallest headways in a linear way is that it does not take into account how the trains are spread over the cycle time. With a cycle time of sixty minutes and four homogeneous trains, one will always have a total sum of (smallest) headways of 60', whether these trains are nicely spread (four 15'intervals; figure 2(a)) or not (e.g. 5', 25', 5' and 25'-intervals; figure 2(b)). However, taking the sum of the reciprocals gives a clear distinction between these situations. In particular, the examples in figure 2 lead to $1 / 15+1 / 15+1 / 15+1 / 15=0.27$, and $1 / 5+1 / 25+1 / 5+1 / 25=0.48$, respectively.
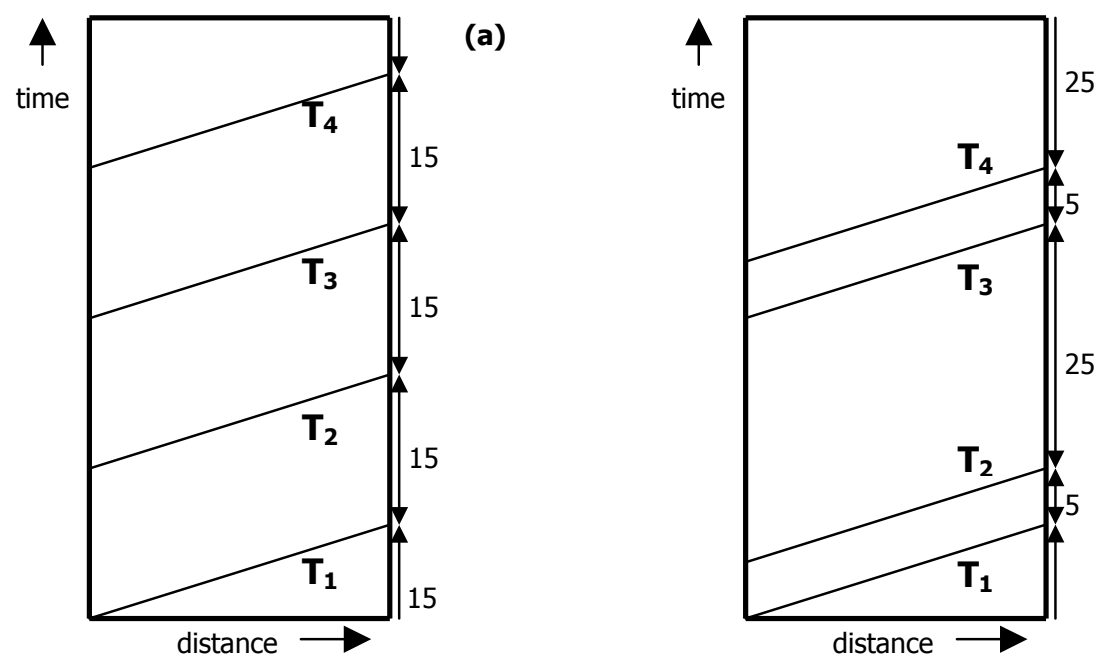

Figure 2: time-distance diagram for two homogeneous situations with a different headway distribution.

This leads to our first heterogeneity measure, based on both the heterogeneity and the spread of the trains over the hour. This measure is applicable to railway tracks between two neighboring railway nodes. The Sum of Shortest Headway Reciprocals (SSHR) is defined as follows:

$$
\operatorname{SSHR}=\sum_{i=1}^{n} \frac{1}{h_{i}^{-}}
$$

with $h_{i}^{-}$the smallest scheduled headway between train $i$ and $i+1$ on the track section, and train $n$ is followed by train 1 , due to cyclicity. It is not difficult to see that, given the number of trains on a certain track section together with their running times, for minimizing the SSHR one should minimize the running time differences between subsequent trains and one should equalize the minimum headways between subsequent trains. If the order of the trains has been prespecified already, then one should equalize the mimimum headways between subsequent trains. 
As stated earlier, the SSHR is not only capable of representing the distribution of the trains over the hour on a track, but it is also capable of including the heterogeneity of these trains on this track. The homogeneous situation in figure 2(a) gives an SSHR of 0.27. The slightly heterogeneous situation in figure 3(a) leads to an SSHR of $1 / 9+1 / 9+1 / 9+1 / 9=0.44$. Figure 3 (b) represents a very heterogeneous situation with an SSHR of $1 / 2+1 / 2+1 / 2+1 / 2=2$.
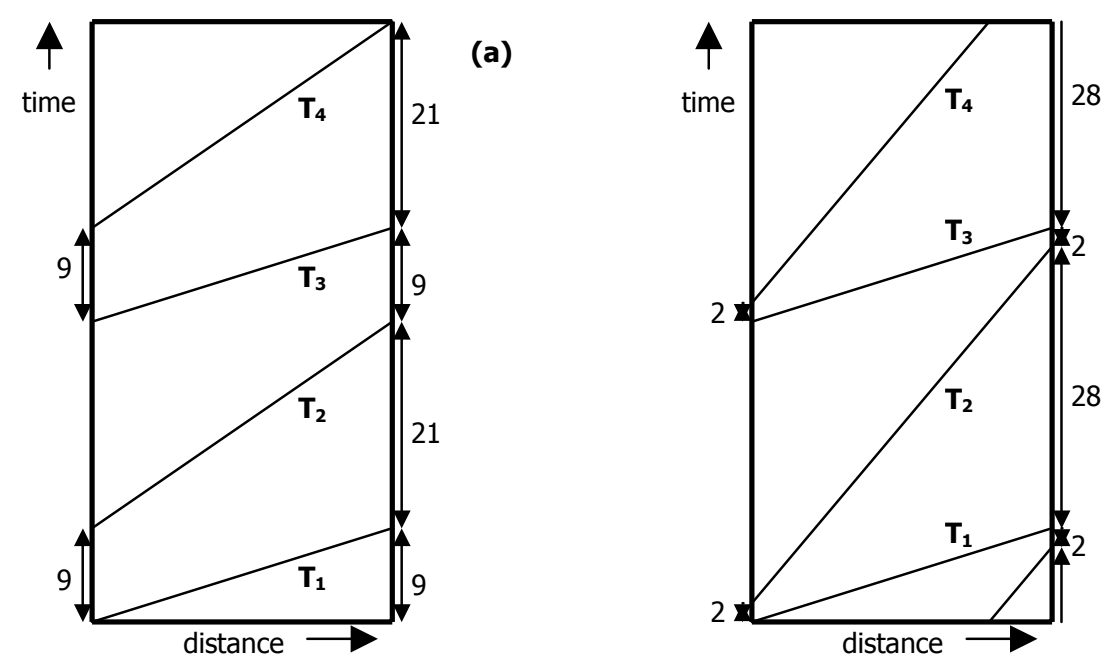

(b)

Figure 3: Two time-distance diagrams with slightly heterogeneous (a) and very heterogeneous (b) railway traffic.

A disadvantage of the SSHR is that headways at departure are penalized as heavily as headways at arrival. However, headways at arrival seem to be more important than headways at departure. The first reason is that delays at arrival are, on average, larger than delays at departure. Secondly, faster long distance trains can be caught behind short distance trains towards the end of a railway section. Therefore we propose a second measure, which only depends on the arrival headways between every pair of subsequent trains, the Sum of Arrival Headway Reciprocals (SAHR):

$$
S A H R=\sum_{i=1}^{n} \frac{1}{h_{i}^{A}}
$$

with $h_{i}^{A}$ the headway at arrival between train $i$ and $i+1$.

In homogeneous cases, the SAHR is equal to the SSHR, so the SAHR is 0.27 in example 2(a) and 0.48 in example 2(b). In heterogeneous cases, the SAHR is always less than the SSHR. The timetables represented in figures 3(a) and 3(b) have an SAHR of $1 / 9+1 / 21+1 / 9+1 / 21=0.32$ and $1 / 2+1 / 28+1 / 2+1 / 28=1.07$, respectively.

Unfortunately, the SAHR does not take into account the track section anymore and it is therefore in fact a single location measure. Still, the arrival distribution can only be nice if the timetable is not too heterogeneous. This means that heterogeneity is implicitly taken into account in the SAHR. However, an improved measure may be attained by taking the weighted average of the two measures above.

The two measures developed above are not absolute measures. They are mainly meant to be able to compare different timetables for the same track or as an indication how to produce a reliable timetable for a certain track. 


\section{Experiments}

In this paper we study the effect of homogenization on the reliability and the punctuality of a railway system. For obtaining more homogeneous timetables, we have chosen the option of shifting stops from the short distance services to the long distance services until the numbers of stops of the trains per track section are as much equal as possible. This leads to more equal running times per track section.

The cyclic timetables were developed with the automatic timetabling tool DONS (Hooghiemstra, 1994). Any real-life or artificial railway network can be defined with this tool. On this infrastructure, train lines can be defined, including their intermediate stops, their rolling stock types, transfer connections and other characteristics. DONS will then provide a feasible timetable, or, if this is not possible, tell which constraints following from the input make a timetable infeasible.

For the comparison of the timetables, simulation of railway traffic has been used. The simulations reported on in this paper are performed with SIMONE. This simulation model is in use both by ProRail, the Dutch railway infrastructure manager, and by Netherlands Railways, the predominant Dutch operator of passenger trains. It is used both for timetable comparisons and for scientific research. A more detailed description of SIMONE is given by Middelkoop and Bouwman $(2000,2001)$.

\section{A theoretical case}

The first case that we are looking at is a theoretical one. Both the simple network and therefore also the timetable are artificial. They were developed especially for the comparison of the heterogeneity and the corresponding reliability.

\section{Case Description}

The network consists of two intersecting double track lines of 192 kilometer each, which intersect at a Central Station (CS). This creates four identical branches of 96 $\mathrm{km}$ : northwest (NW), northeast (NE), southwest (SW), and southeast (SE). The layout of the network is shown in figure 4(a), where the lines do not represent tracks but train lines. The four branches are equal and have three intermediate large stations, where all trains stop. These stations are represented by the rectangles in figures 4(b) and 4(c). Each branch also comprises ten smaller stations, where half of the trains stop. These smaller stations are closer to each other around CS and around the endpoints. One can consider these areas as more densely populated. The distances were chosen such as to resemble the average station distances in the Netherlands. Figure 4 shows the stations where a train line stops: figure 4(b) represents the heterogeneous situation, and figure 4(c) represents the homogeneous situation. Note that the number of trains and the number of stops per station are equal for these two situations.

The intersecting Central Station has free-level crossings only. This means that only trains going to or coming from the same direction can interfere with each other. Still, delays can be transferred throughout the network because of the long distance trains, which alternate in destination. Figure 4(a) shows which direct connections exist in the experiments: each line represents two trains per direction per hour. There are four short distance trains on each branch from CS to the endpoint. Additionally there are four long distance trains per hour on each branch, but they alternate in destination: 
there are two trains per hour from NW96 to SW96, two from NW96 to SE96, two from NE96 to SE96, and two from NE96 to SE96.

Although different types of rolling stock are deployed for short distance trains and for long distance trains in real life, for simplicity only a single type of rolling stock is used in this theoretical case.

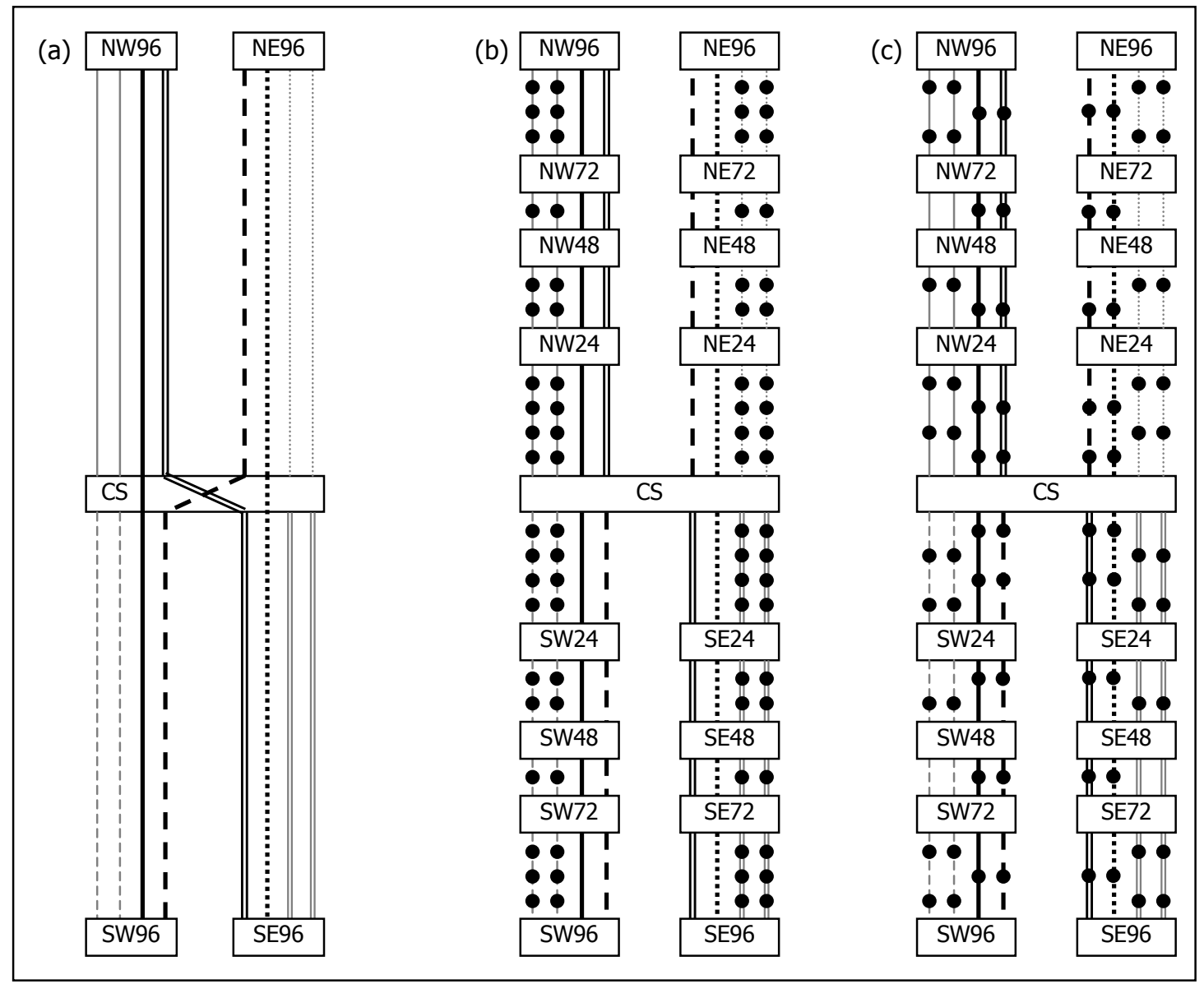

Figure 4: (a) shows the different train connections in the network, with the heterogeneous dwelling pattern in (b) and the homogeneous dwelling pattern in (c).

\section{Heterogeneous Situation}

In the heterogeneous situation, the short distance trains stop at all stations and the long distance trains only dwell at the large stations. This dwelling pattern is shown in figure 4(b). All trains are nicely spread over the hour, which means that from every station in the system, a short distance train leaves every 15 minutes in both directions. At the large stations one can also catch a long distance train exactly every 15 minutes, where the individual long distance lines (for example NW96-SW96), run exactly every 30 minutes. A time-distance diagram created by DONS is given in figure 5 .

The SSHR between CS and one of the endpoints is 5.33 for the heterogeneous case. The SAHR can only be defined for single locations, leading to multiple values. At CS the SAHR is 2.31 from all directions. Coming from CS, the SAHR is also 2.31 at NW48, NE48, SW48 and SE48. Coming from the endpoints, the SAHR is 1.67 at NW48, NE48, SW48 and SE48. Finally, the SAHR is 1.36 at the endpoints.

It should be noted that in heterogeneous situations, overtaking may have to take place, depending on the frequency, the difference in numbers of stops and the time loss per 
additional stop. In the presented case, overtaking is necessary indeed: the short distance trains are overtaken by the long distance trains in NW48, NE48, SW48 and SE48. Furthermore, the dwell time of the long distance trains is extended at NW24, NE24, SW24 and SE24 to decrease the travel time differences. Otherwise no feasible timetable would exist for these trains, these dwellings, and this train order.

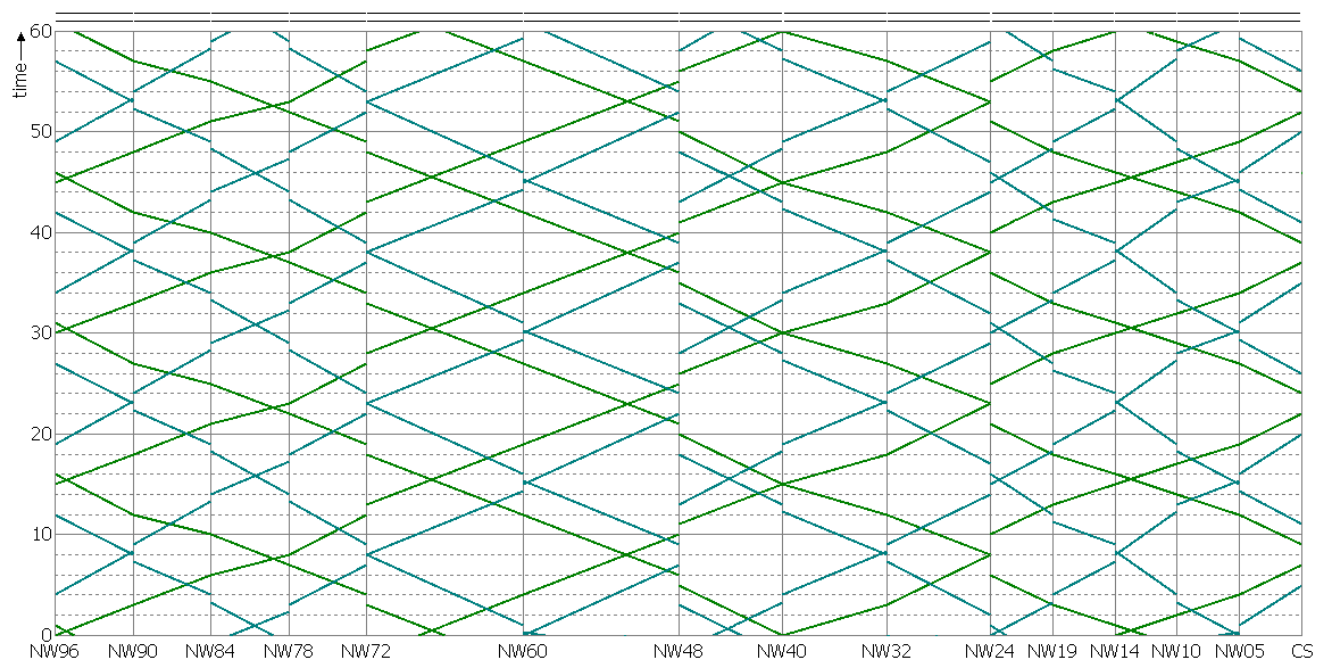

Figure 5: Time-space diagram of the heterogeneous situation for the branch NW96-CS: there is an apparent difference between the long distance trains -the flatter lines-and the short distance trains the steeper lines. Vertical jumps in the lines depict stops at stations. Due to acceleration, deceleration and roundings, running times on tracks of equal length may differ from each other. The other three branches have identical time-space diagrams.

\section{Homogeneous Situation}

In the homogeneous situation, the same number of lines, the same number of stops per station, and the same line-endpoint connections are applied as in the heterogeneous situation. Also the same type of rolling stock is used. However, a more homogeneous situation is created by decreasing the number of stops of the short distance services and by increasing the number of stops of the long distance services until both are as equal as possible. The newly created services are shown in figure 4(c).

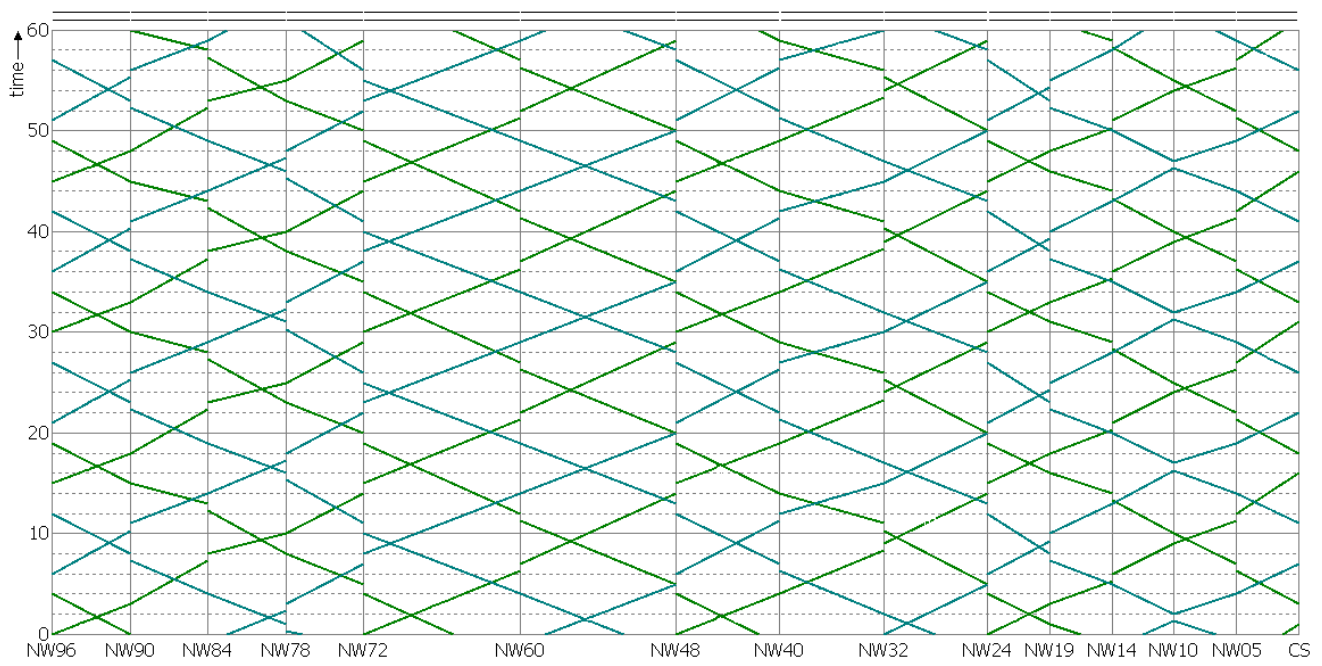

Figure 6: Time-space diagram of the homogeneous situation: the different trains have almost parallel time-space diagrams, which leads to a larger minimal headway between trains. 
Per branch, starting from the endpoints, the long distance lines dwell at the $2^{\text {nd }}, 4^{\text {th }}$, $6^{\text {th }}, 8^{\text {th }}$, and $10^{\text {th }}$ small station, whereas the short distance lines (NW96-CS and so on) dwell at the $1^{\text {st }}, 3^{\text {rd }}, 5^{\text {th }}, 7^{\text {th }}$, and $9^{\text {th }}$ small station. Again, every small station is served four times an hour, exactly every 15 minutes, and each intercity station is served eight times per hour as is shown in figure 6 .

The homogeneous situation reduces the heterogeneity measures significantly. For each of the branches, the SSHR goes down from 5.33 to 1.24. At CS the SAHR decreases from 2.31 to 1.11. At NW48, NE48, SW48 and SE48, we see the SAHR dropping from 2.31 to 1.07 (from CS), and from 1.67 to 1.11 (from the endpoints). The SAHR at the endpoints decreases from 1.36 to 1.07.

\section{Experimental Design}

Sixteen experiments with different primary delay distributions were carried out. The primary delays are generated randomly by SIMONE, following the specifications given in table 1a. Dwell times and running times are disturbed with a certain probability. These disturbances are exponentially distributed with a given average. Earlier research (Goverde et al., 2001) shows that real dwell time disturbances and late arrivals fit well to an exponential distribution.

\begin{tabular}{|c|c|c|c|c|c|c|c|}
\hline \multirow[b]{2}{*}{ 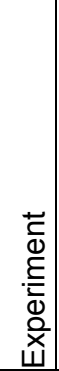 } & \multicolumn{2}{|c|}{$\begin{array}{l}\text { DWELL TIME } \\
\text { DISTURBANCE } \\
\text { [all stations] }\end{array}$} & \multicolumn{2}{|c|}{$\begin{array}{c}\text { DWELL TIME } \\
\text { DISTURBANCE } \\
\text { [large stations] }\end{array}$} & \multicolumn{2}{|c|}{$\begin{array}{l}\text { RUNNING TIME } \\
\text { DISTURBANCE }\end{array}$} & \multirow{2}{*}{ 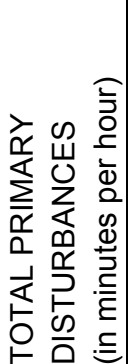 } \\
\hline & 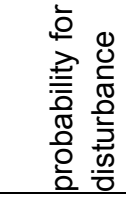 & 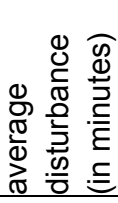 & 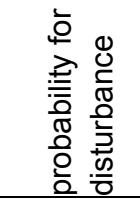 & 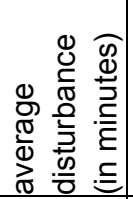 & 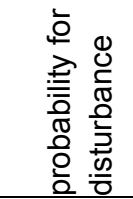 & 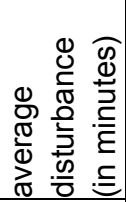 & \\
\hline 1 & $5 \%$ & 1 & & & & & 30.8 \\
\hline 2 & $5 \%$ & 1 & $5 \%$ & 2 & & & 61.7 \\
\hline 3 & $5 \%$ & 1 & $10 \%$ & 2 & & & 92.3 \\
\hline 4 & $5 \%$ & 1 & $15 \%$ & 2 & & & 123.0 \\
\hline 5 & $5 \%$ & 1 & $20 \%$ & 2 & & & 152.9 \\
\hline 6 & $5 \%$ & 1 & $25 \%$ & 0.5 & & & 69.5 \\
\hline 7 & $5 \%$ & 1 & $25 \%$ & 1 & & & 107.6 \\
\hline 8 & $5 \%$ & 1 & $25 \%$ & 1.5 & & & 146.2 \\
\hline 9 & $5 \%$ & 1 & $25 \%$ & 2 & & & 183.4 \\
\hline 10 & & & $25 \%$ & 1 & & & 76.3 \\
\hline 11 & & & $25 \%$ & 1 & $20 \%$ & 0.075 & 128.1 \\
\hline 12 & & & $25 \%$ & 1 & $40 \%$ & 0.075 & 179.5 \\
\hline 13 & & & $25 \%$ & 1 & $60 \%$ & 0.075 & 232.2 \\
\hline 14 & & & $25 \%$ & 1 & $10 \%$ & 0.15 & 128.5 \\
\hline 15 & & & $25 \%$ & 1 & $20 \%$ & 0.15 & 179.3 \\
\hline 16 & & & $25 \%$ & 1 & $30 \%$ & 0.15 & 232.1 \\
\hline
\end{tabular}

Table 1a: the experiments and their primary disturbances

All simulation experiments consist of fifty runs of 1320 minutes, including 120 minutes of warm-up time. This leaves exactly fifty times twenty hours of simulation time for which statistics are collected. Twenty hours is close to one day of train services in the Netherlands, where night services are almost non-existing. The use of fifty runs leads to a satisfactory reliability of the simulation results, where the average delays have standard deviations up to $3 \%$ for the heterogeneous situation and up to 
$7 \%$ for the homogeneous situation (except for experiment 1, where small chances for disturbances cause a higher variability of the results).

The first experiments have a combination of dwell time disturbances at all stations and dwell time disturbances at the large stations. This leads to two cumulative disturbances for the large stations. Experiments 1 to 5 have an increasing probability for disturbances at the large stations; experiments 1 and 6 to 9 have an increasing average size of the dwell time disturbances at the large stations.

The following experiments have a combination of dwell time disturbances at the large stations and running time disturbances. Experiments 11 to 13 have the same total number of primary delay minutes as experiments 14 to 16 , but the latter experiments have fewer, though larger, disturbances.

\section{Results:}

- Table $1 \mathrm{~b}$ shows that, going from the heterogeneous to the homogeneous situation, the average delays decrease significantly. Although a decrease was expected, the extent is surprisingly large: over $65 \%$ in all experiments. Even more surprising is the consistency of these results. Although the decrease in dispunctuality is varying quite a bit, the average delays always decrease with 66 to 77 percent.

\begin{tabular}{|c|c|c|c|c|c|c|c|c|c|}
\hline \multirow[b]{2}{*}{ 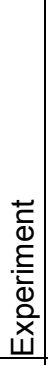 } & \multicolumn{3}{|c|}{$\begin{array}{c}\text { AVERAGE ARRIVAL DELAY } \\
\text { (per train measurement in } \\
\text { minutes) }\end{array}$} & \multicolumn{3}{|c|}{$\begin{array}{c}\text { 3-MINUTE } \\
\text { DISPUNCTUALITY } \\
\text { (\% of trains delayed) }\end{array}$} & \multicolumn{3}{|c|}{$\begin{array}{l}\text { TOTAL INCURRED } \\
\text { SECONDARY DELAYS } \\
\text { (in minutes) }\end{array}$} \\
\hline & 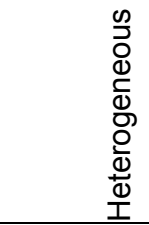 & 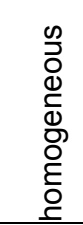 & 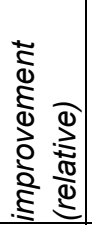 & 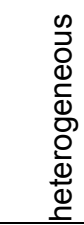 & 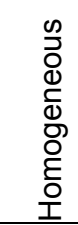 & 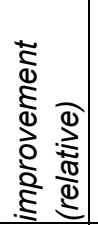 & $\begin{array}{l}0 \\
0 \\
0 \\
\Phi \\
\Phi \\
0 \\
0 \\
\frac{0}{0} \\
\frac{1}{\Phi} \\
\end{array}$ & 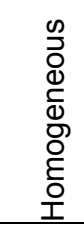 & 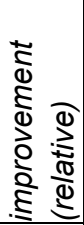 \\
\hline 1 & 0.38 & 0.09 & 76.5 & 2.1 & 0.5 & 75.0 & 36.9 & 0.5 & 98.7 \\
\hline 2 & 0.97 & 0.27 & 72.4 & 6.9 & 2.5 & 64.2 & 88.2 & 4.4 & 95.0 \\
\hline 3 & 1.57 & 0.46 & 70.7 & 11.7 & 4.8 & 59.3 & 136.0 & 9.1 & 93.3 \\
\hline 4 & 2.16 & 0.65 & 69.9 & 16.1 & 6.9 & 57.0 & 177.5 & 13.4 & 92.4 \\
\hline 5 & 2.70 & 0.88 & 67.5 & 20.1 & 9.7 & 51.7 & 212.5 & 18.3 & 91.4 \\
\hline 6 & 0.64 & 0.15 & 76.8 & 3.8 & 0.7 & 82.5 & 69.9 & 0.6 & 99.2 \\
\hline 7 & 1.38 & 0.33 & 76.3 & 9.6 & 2.3 & 76.0 & 129.0 & 2.1 & 98.4 \\
\hline 8 & 2.38 & 0.65 & 72.5 & 17.3 & 6.6 & 61.8 & 195.8 & 9.8 & 95.0 \\
\hline 9 & 3.21 & 1.08 & 66.4 & 23.6 & 12.2 & 48.3 & 243.1 & 22.5 & 90.7 \\
\hline 10 & 0.92 & 0.21 & 77.0 & 5.9 & 1.2 & 79.1 & 83.9 & 1.1 & 98.7 \\
\hline 11 & 1.28 & 0.32 & 75.3 & 8.3 & 1.9 & 77.0 & 117.3 & 1.5 & 98.8 \\
\hline 12 & 1.73 & 0.46 & 73.4 & 11.4 & 3.0 & 73.8 & 152.6 & 2.0 & 98.7 \\
\hline 13 & 2.28 & 0.66 & 70.9 & 15.4 & 4.7 & 69.8 & 188.8 & 3.0 & 98.4 \\
\hline 14 & 1.53 & 0.38 & 75.0 & 10.4 & 2.5 & 75.8 & 135.9 & 2.1 & 98.5 \\
\hline 15 & 2.20 & 0.60 & 72.8 & 15.4 & 4.7 & 69.8 & 184.4 & 3.7 & 98.0 \\
\hline 16 & 2.99 & 0.88 & 70.6 & 21.3 & 8.0 & 62.4 & 234.9 & 6.0 & 97.4 \\
\hline
\end{tabular}

Table 1b: the results of the experiments. The presented average delays have standard deviations between $0.26 \%$ and $2.65 \%$ in the heterogeneous case, and between $0.76 \%$ and $7.00 \%$ in the homogeneous case, with the exception of experiment 1 (6.21\% and $18.38 \%$ respectively).

- The last three columns of table $1 \mathrm{~b}$ show where the differences originate from, namely the reduction in the secondary delays. Especially in experiments with only few and small primary delays, there are hardly any secondary delays in the homogeneous situation. A simple explanation for this is the fact that secondary delays only emerge if there are "large" primary delays. The smallest planned 
headway between trains in the homogeneous situation is six minutes, and the minimally required headway is only two minutes. This allows for at least four minutes of primary delay for a certain train before it causes secondary delays to subsequent trains. In the heterogeneous situation, the slightest primary delay causes secondary delays already, because trains are scheduled at minimum headway time.

- When average delays are smaller, the relative improvement is higher. This is probably because the homogeneous situation is relatively immune for small delays, as was explained in the previous paragraph. When the delays increase, secondary delays may also occur in the homogeneous situation, thereby reducing the relative difference with the heterogeneous situation.

- Additionally, few large primary delays are more hurtful to the punctuality than many small primary delays with the same total number of minutes of initial delays. Compare for example experiments 11, 12 and 13 with experiments 14, 15 and 16 . The total primary delays in minutes are equal, but the average size of a primary running time delay is twice as large in the latter experiments. This leads to an average delay increase of $20 \%$ to $30 \%$.

Two explanations may be viable here. First, the explanation above is valid again: where a small primary delay is too small to disrupt a second train, this is valid for two small delays on two different trains as well. However, one large delay may have a negative effect on several other trains.

Secondly, two separate primary delays are recovered by two separate running time supplements. Suppose in situation 1, that one train, running from A via B, C and $\mathrm{D}$ to $\mathrm{E}$, is delayed 2 minutes at station $\mathrm{A}$ and between every pair of stations half a minute can be recovered. Then there will be a 1.5 minute delay at station $\mathrm{B}$, one minute at $\mathrm{C}$, half a minute at $\mathrm{D}$, and the train will arrive on time at station $\mathrm{E}$. The average arrival delay is $(1.5+1+0.5+0) / 4=0.75$ minutes. A second train, also running from $\mathrm{A}$ to $\mathrm{E}$, is not delayed at all. The average arrival delay of these two trains is 0.375 minutes. Now in situation 2 , let us take two trains for the same line, which both have a one-minute primary delay at A. They will both be 30 seconds delayed at station $\mathrm{B}$, but they will arrive on time at stations $\mathrm{C}, \mathrm{D}$ and $\mathrm{E}$. This results in an average arrival delay of only $2 \times(0.5+0+0+0) / 8=0.125$ minute.

- The dwell time disturbance at all stations has the largest impact on trains with many stops. This means that the expected travel time increase is largest for the short distance trains in the heterogeneous situation. Therefore, the expected travel time differences are even larger than the planned travel time differences.

\section{Causes for delays in the heterogeneous situation}

Finding out where the delays come from may provide useful information. Therefore the average delays over the course of the train services were examined. Figure 7 shows the average delays on one of the four branches, separated by trains running towards CS (indicated by $a$ ), and running from CS (indicated by $b$ ). This is the graph for experiment 3 , but it is typical for all experiments in the heterogeneous case.

- The first thing to notice is the fact that the short distance trains are hardly delayed at all, while long distance trains may have considerable delays. This is because a long distance train can be caught behind a short distance train. In that case, the long distance train can incur large secondary delays, because it cannot run any faster than the short distance train up to the next station where overtaking is possible. However, a short distance train can never be caught behind a slower train. This is exactly why the SAHR was developed next to the SSHR. 
The largest delays of short distance trains are found at the first station after starting from CS. This is explained by the delays of the long distance trains in CS, which hamper the departure of the short distance trains starting from CS.

- The average delays of the long distance trains increase with the distance traveled, but not linearly. The largest delay increases can be found just before CS and b48. This is exactly where the heterogeneity causes the headways to be smallest (see figure 5) and the express trains catch up with the short distance trains. The two other locations where the express trains catch up with the short distance trains, a48 and b96, seem to cause less problems. This is due to the lower heterogeneity, and consequently the larger headways, in the peripheral areas.

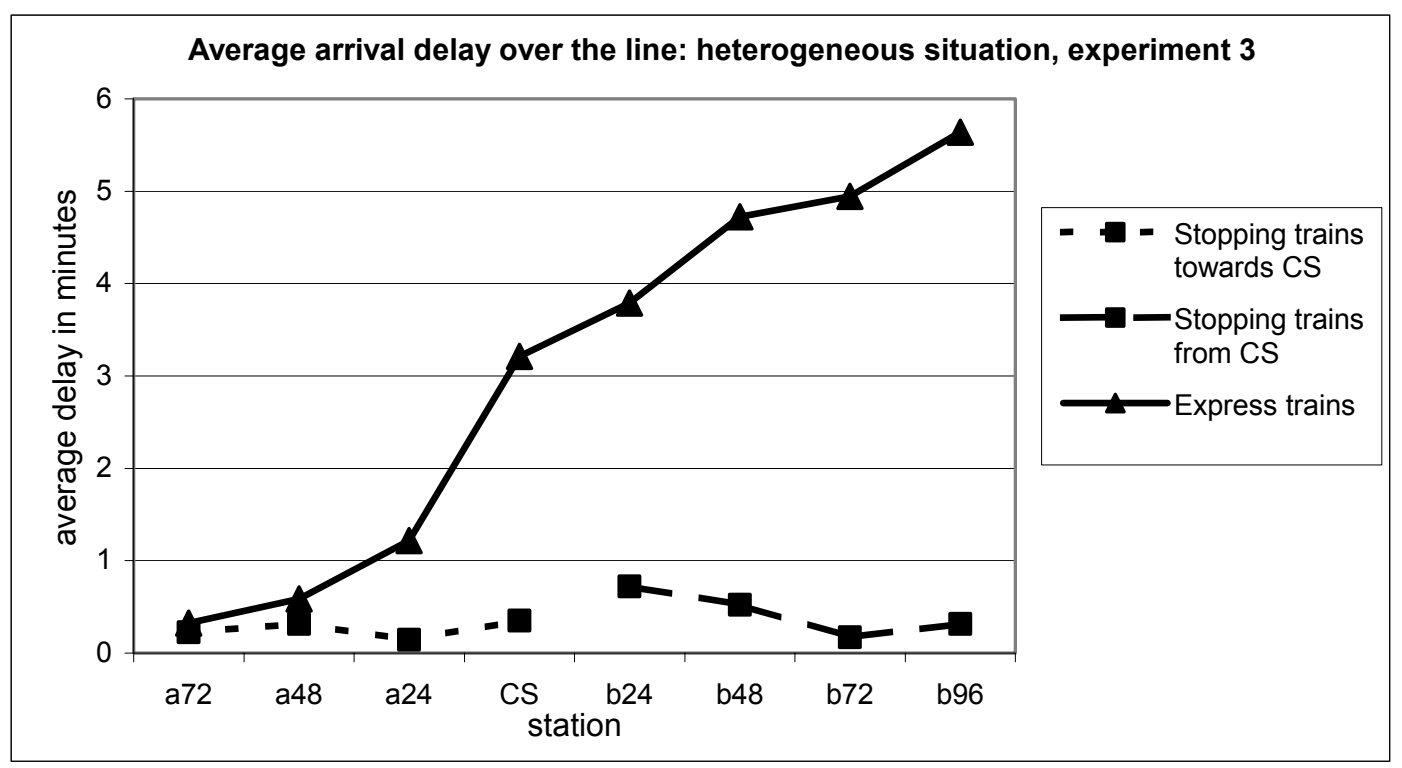

Figure 7: average delay over the course of the lines. For example, a 72 shows the average arrival delay at NW72, NE72, SW72 and SE72 for trains towards CS. b48 gives the average delay for arrivals at NW48, NE48, SW48 and SE48 for trains going towards the endpoints.

\section{A practical case}

Besides the theoretical case presented in section 4, a practical case has been worked out also. We compared a real-life heterogeneous timetable with a more homogeneous timetable for a busy line in the Netherlands. Some details of the real timetable have been adjusted slightly for the simulations (Nederlandse Spoorwegen, 2002).

The case which is elaborated here consists of the lines from The Hague Central (Gvc) and Rotterdam Central (Rtd) to Utrecht Central (Ut), which merge at Moordrecht Junction (Mda). These lines are represented by the bold lines in figure 8 . This part of the network has double track everywhere, except for the section between Moordrecht Junction and Gouda Goverwelle (Gdg), which has four parallel tracks. Moordrecht Junction is a non-level crossing. The distance between The Hague and Utrecht is $61 \mathrm{~km}$ and the distance between Rotterdam and Utrecht is $55.8 \mathrm{~km}$. 


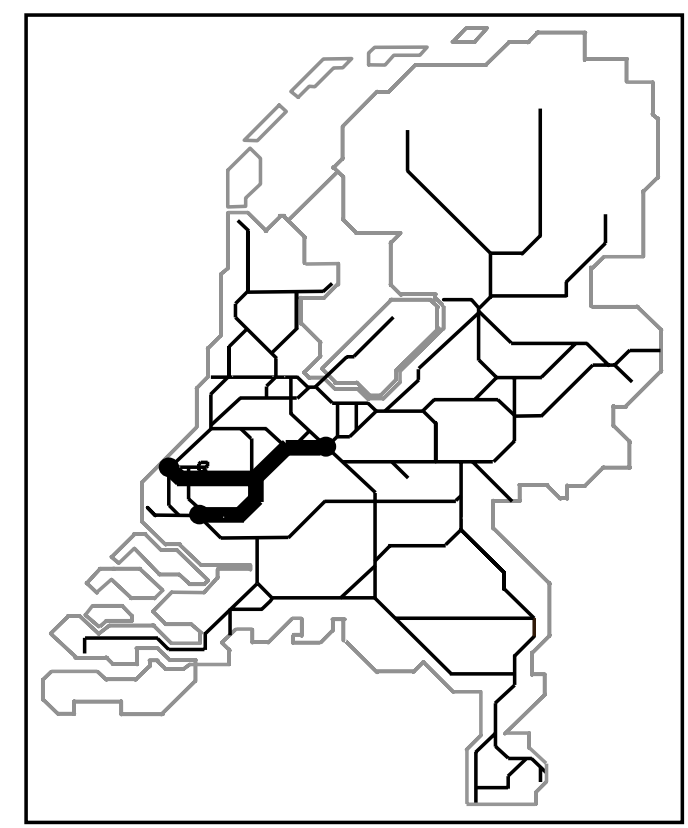

Figure 8: the railway network served by Netherlands Railways. The bold lines represent the tracks between The Hague and Utrecht and between Rotterdam and Utrecht that are considered in the case.

The lines that are operated on these tracks are shown in figure 9. All lines have a cycle time of 30 minutes, which leads to, for example, eight trains per hour between Rotterdam Central and Moordrecht Junction, and twelve trains per hour between Woerden (Wd) and Utrecht Central.

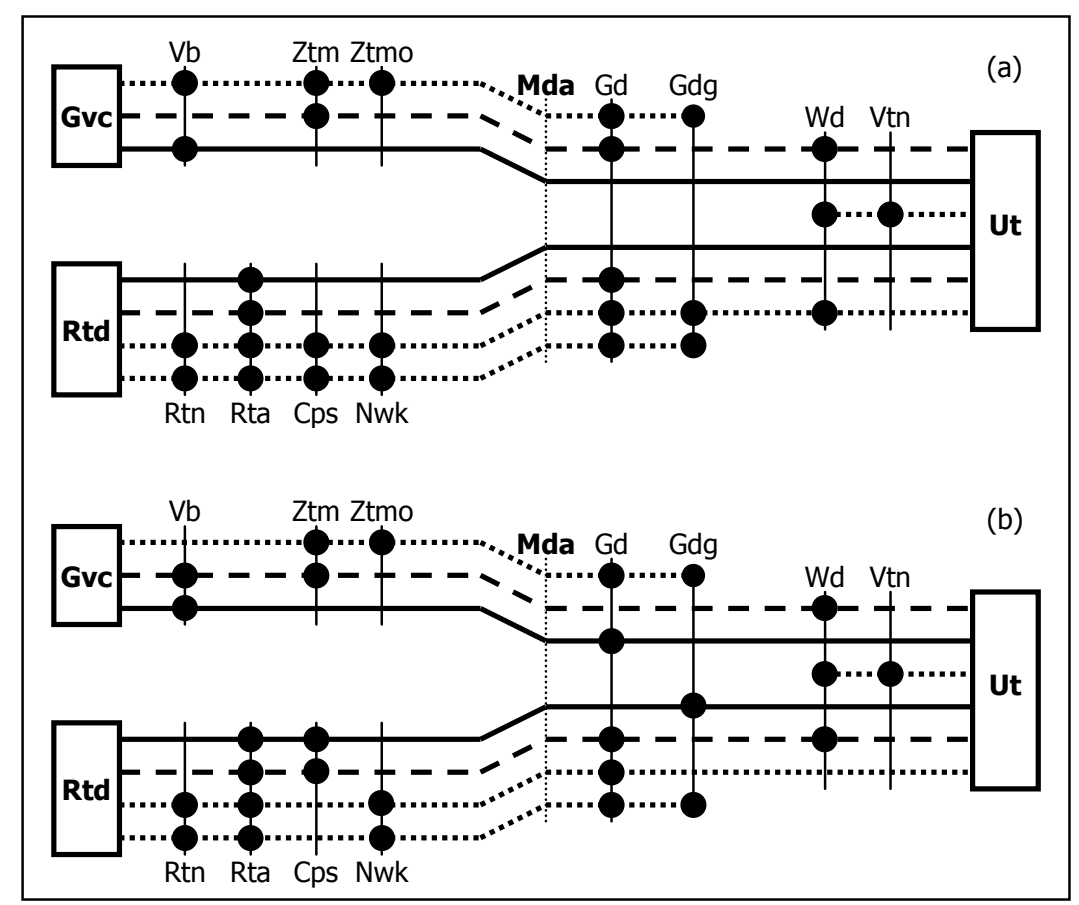

Figure 9: Train lines and dwelling patterns of the heterogeneous situation (a) and the homogeneous situation (b) of the practical case. Besides the junction Mda, all abbreviations indicate a station. 


\section{Heterogeneous situation}

With some adjustments, the 2003 rush hour timetable has been taken for the heterogeneous situation (Nederlandse Spoorwegen, 2002). Cargo trains are skipped, resulting in a three-train-system: long distance trains, interregional trains and short distance trains, represented in figure 9 by solid $(-)$, dashed $(---)$, and dotted lines $(\cdots \cdots \cdots \cdot)$, respectively.

Every 30 minutes there is one short distance train from Gvc to Gdg, there is one interregional train from Gvc to Ut, and there is one long distance train from Gvc to Ut. Starting from Rtd, there is one short distance train running to Gdg, a second short distance train running to Ut (not dwelling at Vleuten (Vtn)), one interregional train to Ut, and one long distance train to Ut. Additionally there is a short distance train from Wd to Ut. This adds up to 16 trains per hour per direction.

Unlike the theoretical case, the lines in this case are run by different rolling stock types. These rolling stock types have their own specific characteristics concerning acceleration and top speed. These are, according to the real-life situation, matched with the service provided.

\section{Homogeneous situation}

As in the theoretical case, the heterogeneous situation is homogenized by decreasing the number of stops of the short distance services and by compensating those by additional stops of the faster services. In the end, the total number of stops per station is equal in both situations. The final dwell pattern is shown in figure 9(b).

Because of the homogenization, there is no clear distinction anymore between slower and faster services. Therefore, the necessity for different types of rolling stock has gone. However, for a fair comparison, the same rolling stock has been used for both situations. The SSHR and the SAHR for the practical case are given in table 2.

\begin{tabular}{|c|c|c|c|}
\hline \multicolumn{2}{|c|}{ SSHR } & \multirow{2}{*}{$\begin{array}{l}\text { Hetero- } \\
\text { geneous }\end{array}$} & \multirow{2}{*}{$\begin{array}{l}\text { Homo- } \\
\text { geneous }\end{array}$} \\
\hline from & to & & \\
\hline Gvc & $\mathrm{Gd}$ & 0.76 & 0.67 \\
\hline Rtd & $\mathrm{Gd}$ & 3.18 & 1.47 \\
\hline $\mathrm{Gd}$ & Ut & 3.47 & 2.97 \\
\hline Ut & Gdg & 5.52 & 3.02 \\
\hline $\mathrm{Gd}$ & Gvc & 1.06 & 0.69 \\
\hline $\mathrm{Gd}$ & Rtd & 2.83 & 1.19 \\
\hline
\end{tabular}

\begin{tabular}{|c|c|c|c|}
\hline \multicolumn{2}{|c|}{ SAHR } & \multirow{2}{*}{$\begin{array}{l}\text { Hetero- } \\
\text { geneous }\end{array}$} & \multirow{2}{*}{$\begin{array}{l}\text { Homo- } \\
\text { geneous }\end{array}$} \\
\hline from & to & & \\
\hline Gvc & $\mathrm{Gd}$ & 0.64 & 0.62 \\
\hline Rtd & $\mathrm{Gd}$ & 1.36 & 1.17 \\
\hline $\mathrm{Gd}$ & Ut & 2.70 & 2.52 \\
\hline Ut & Gdg & 2.55 & 1.77 \\
\hline $\mathrm{Gd}$ & Gvc & 0.67 & 0.61 \\
\hline $\mathrm{Gd}$ & Rtd & 1.74 & 1.07 \\
\hline
\end{tabular}

Table 2: Tables of SSHR and SAHR for the different tracks between The Hague, Rotterdam and Utrecht

Experimental Design

Again, the simulation experiments consist of fifty runs of 1320 minutes, including 120 minutes of warm-up time. The primary delay distributions, all exponential again, are given in table $3 \mathrm{a}$. 


\begin{tabular}{|c|c|c|c|c|c|c|}
\hline \multirow[b]{2}{*}{ 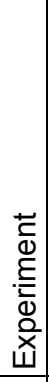 } & \multicolumn{2}{|c|}{$\begin{array}{l}\text { DWELL TIME } \\
\text { DISTURBANCE } \\
\text { [all stations] }\end{array}$} & \multicolumn{2}{|c|}{$\begin{array}{c}\text { ABSOLUTE } \\
\text { RUNNING TIME } \\
\text { DISTURBANCE }\end{array}$} & $\begin{array}{c}\text { RELATIVE } \\
\text { RUNNING TIME } \\
\text { DISTURBANCE }\end{array}$ & \multirow{2}{*}{ 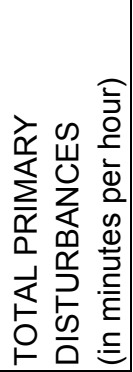 } \\
\hline & 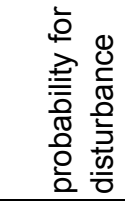 & 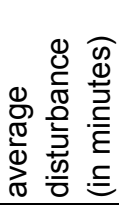 & 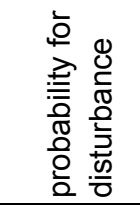 & 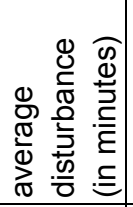 & 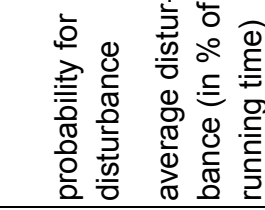 & \\
\hline 1 & $100 \%$ & 0.6 & & & & 95.9 \\
\hline 2 & $100 \%$ & 0.8 & & & & 128.0 \\
\hline 3 & $10 \%$ & 1 & $5 \%$ & 1 | & & 38.7 \\
\hline 4 & $20 \%$ & 1 & $10 \%$ & 1 & & 78.2 \\
\hline 5 & $50 \%$ & 0.5 & $20 \%$ & 0.5 & & 86.2 \\
\hline 6 & $75 \%$ & 0.5 & $30 \%$ & 0.5 & & 129.2 \\
\hline 7 & & & & & $30 \%$ & 112.8 \\
\hline 8 & & & & & $60 \%$ & 114.0 \\
\hline 9 & $20 \%$ & 1 & & & $30 \%$ & 89.3 \\
\hline 10 & $50 \%$ & 0.5 & & & $30 \%$ & 96.9 \\
\hline
\end{tabular}

Table 3a: the experiments and their primary disturbances

The first two experiments have dwell time disturbances at all stations. The next four experiments have a combination of dwell time disturbances and absolute running time disturbances. Absolute running time disturbances are independent of the running time and have the averages given in table 3a. The disturbances of experiments 5 and 6 have a larger probability of occurring, but are smaller than those of experiments 3 and 4 .

Experiments 7 and 8 have relative running time disturbances, which depend on the scheduled running times of the trains on the track. The average delay equals a certain percentage of the running time. Although the total primary delays are equal, experiment 8 has more but smaller disturbances than experiment 7 . Experiments 9 and 10 have both dwell time disturbances and relative running time disturbances.

\begin{tabular}{|c|c|c|c|c|c|c|c|c|c|}
\hline \multirow[b]{2}{*}{ 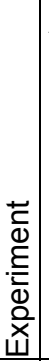 } & \multicolumn{3}{|c|}{$\begin{array}{c}\text { AVERAGE ARRIVAL DELAY } \\
\text { (per train measurement in } \\
\text { minutes) }\end{array}$} & \multicolumn{3}{|c|}{$\begin{array}{c}\text { 3-MINUTE } \\
\text { DISPUNCTUALITY } \\
\text { (\% of trains delayed })\end{array}$} & \multicolumn{3}{|c|}{$\begin{array}{l}\text { TOTAL INCURRED } \\
\text { SECUNDARY DELAYS } \\
\text { (in minutes per hour) }\end{array}$} \\
\hline & 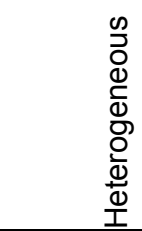 & 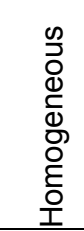 & 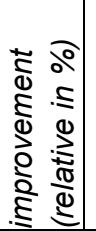 & $\begin{array}{l}0 \\
0 \\
0 \\
\Phi \\
\Phi \\
\Phi \\
\frac{1}{\Phi} \\
\frac{1}{\Phi} \\
\frac{1}{I}\end{array}$ & 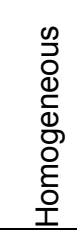 & 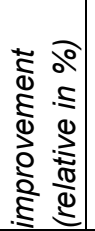 & $\begin{array}{l}0 \\
0 \\
0 \\
0 \\
\frac{1}{0} \\
0 \\
0 \\
\frac{1}{0} \\
\frac{1}{0} \\
\frac{1}{1}\end{array}$ & 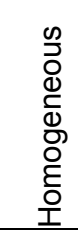 & 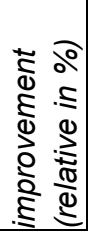 \\
\hline 1 & 1.08 & 0.72 & 33.4 & 8.8 & 3.1 & 64.6 & 30.0 & 3.2 & 89.3 \\
\hline 2 & 1.85 & 1.22 & 34.0 & 21.1 & 10.4 & 50.8 & 50.3 & 8.4 & 83.4 \\
\hline 3 & 0.60 & 0.40 & 33.7 & 5.0 & 3.0 & 39.9 & 20.9 & 4.2 & 80.2 \\
\hline 4 & 1.40 & 0.92 & 34.5 & 15.0 & 9.0 & 39.9 & 41.3 & 10.8 & 74.0 \\
\hline 5 & 1.13 & 0.75 & 33.6 & 8.7 & 3.9 & 55.4 & 28.8 & 3.9 & 86.6 \\
\hline 6 & 2.02 & 1.35 & 33.2 & 23.1 & 12.0 & 48.2 & 47.5 & 8.7 & 81.7 \\
\hline 7 & 2.21 & 1.55 & 29.9 & 25.9 & 17.6 & 32.1 & 60.2 & 22.9 & 62.0 \\
\hline 8 & 1.71 & 1.22 & 28.6 & 18.3 & 10.8 & 41.1 & 38.7 & 10.4 & 73.1 \\
\hline 9 & 1.30 & 0.89 & 31.4 & 12.4 & 7.5 & 39.6 & 35.0 & 8.7 & 75.2 \\
\hline 10 & 1.28 & 0.88 & 31.0 & 11.4 & 5.9 & 48.0 & 32.1 & 6.3 & 80.4 \\
\hline
\end{tabular}

Table $3 b$ : the results of the practical case. The average delays have standard deviations between $0.3 \%$ and $2.4 \%$ in the heterogeneous case, and between $0.3 \%$ and $3.3 \%$ in the homogeneous case. 
SSHR, SAHR and the results

The results of the practical case are shown in table $3 \mathrm{~b}$. The results are comparable with those of the theoretical case. The main distinction is that the decrease in delays between the heterogeneous and the homogeneous situation is smaller. This is easily explained by the smaller differences in heterogeneity in the practical case.

Furthermore, figures $10 \mathrm{a}$ and $10 \mathrm{~b}$ show the improvements in the SSHR and in the SAHR in comparison with the delay reductions. For this comparison, the network has been divided into six sections: Gvc-Gd, Rtd-Gd and Gd-Ut and vice versa. The average delay for each section, as given in the figures, is the average delay of all trains at the endpoint of the section minus the average delay of these trains at the start of the section. Thus it is the increase in average delay on the corresponding section.

The upper right of each line-segment in figure 10a, represented by a circle, is the SSHR and the average delay in the homogeneous situation. The other endpoint, represented by a square, is the result of the homogenization. Figure $10 \mathrm{~b}$ shows the same comparison for the SAHR. The graphs represent the results of experiment 7, but the graphs for the other experiments are quite similar.

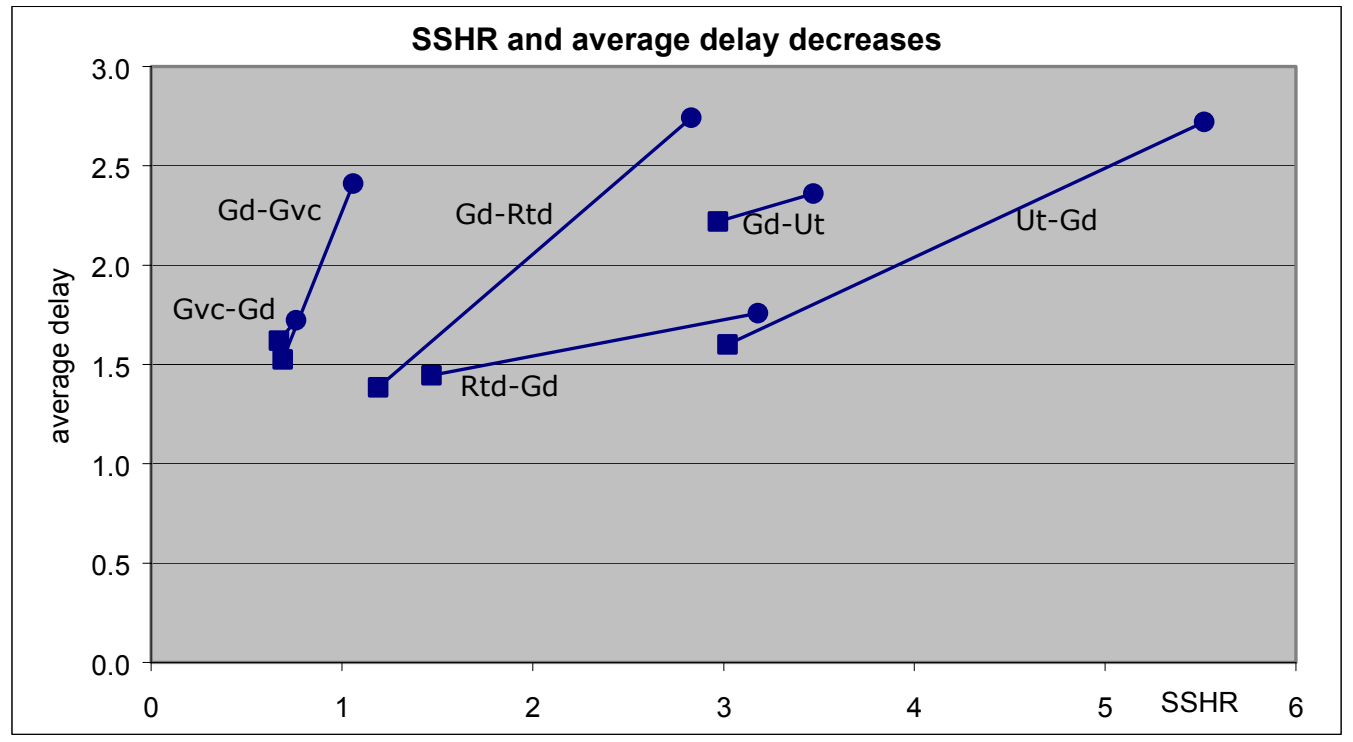

Figure 10a: The relation between the decrease in SSHR and the reduction of the average delay.

- Figures $10 \mathrm{a}$ and $10 \mathrm{~b}$ show that homogenization of the timetable leads to a reduction both in the SSHR and in the SAHR. It also shows that it leads to a reduction in the average delays on all track sections.

- The decrements in the SSHR are quite different for the different track sections: Gvc-Gd only shows a small difference, while Ut-Gd shows a large decrease. The same is true for the SAHR.

- The relative reductions in the SSHR are not equal, or almost equal, to those of the SAHR. This means that the SSHR and the SAHR are two rather distinct measures. See for example the track section Rtd-Gd.

- In general, a larger decrease in the SSHR leads to a larger reduction in the delays. Still, the line-segments in Figure 10a for the track sections Rtd-Gd and Gd-Ut are rather flat. This means that the delays do not always decrease as much as the SSHR suggests. Therefore the SSHR can be used as an indication in what direction the reliability goes, but it is not an absolute measure. 


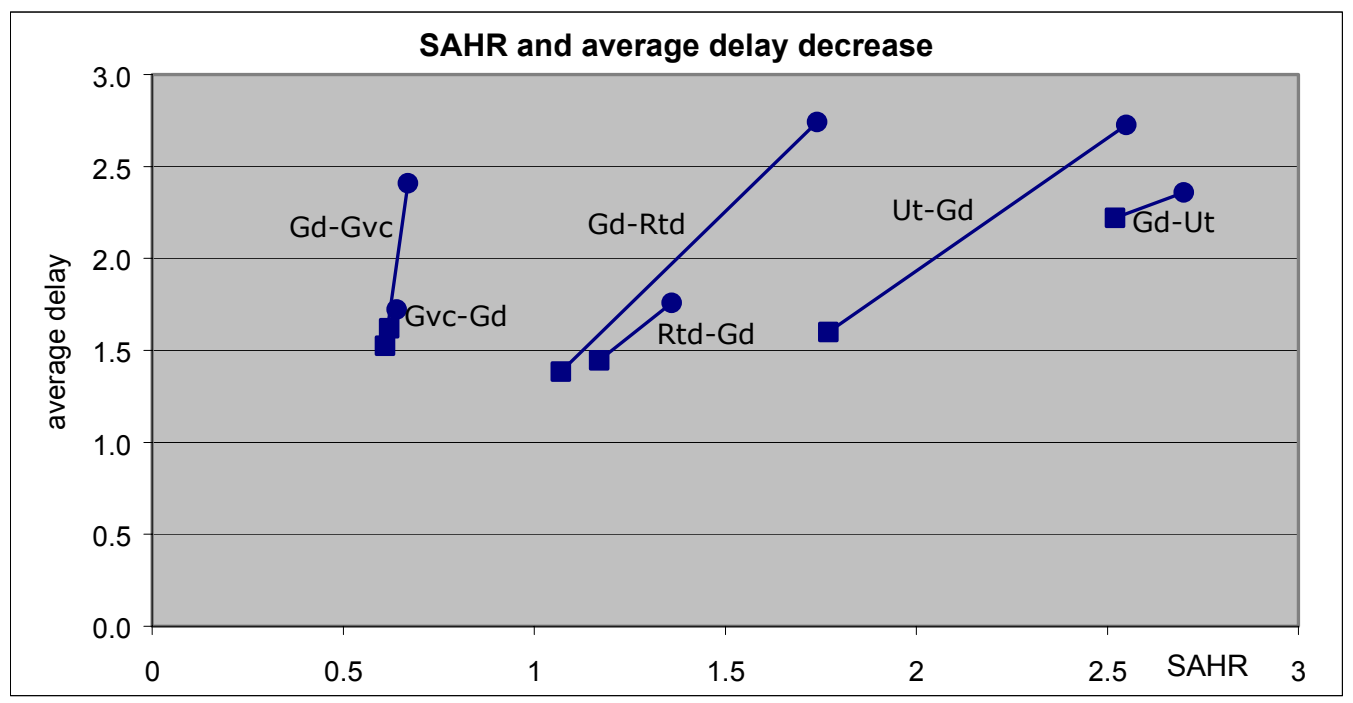

Figure 10b: The relation between the decrease in SAHR and the reduction of the average delay.

For the starting sections, the departure reliability from the first stations is very high. This means that small departure headways hardly have a negative influence on the reliability. The reduction of the SSHR on Rtd-Gd is mainly based on a fairer distribution of the departures; arrivals are hardly affected by the homogenization. This may explain the relatively small reliability improvement of this section.

- Also, a larger decrease in the SAHR leads to a larger reduction in delays. Still, sections with a relatively large delay reduction can be observed (e.g. Gd-Gvc), as well as sections with a relatively small delay reduction (e.g. Gd-Ut).

Due to the large reduction of the delays on the section Ut-Gd, predicted by the SAHR, there is also a large reduction in the departure delays for the section GdGvc. A better starting reliability implies fewer secondary delays, which explains the large delay reduction on Gd-Gvc, and, to a lesser extent, on Gd-Rtd.

\section{Discussion}

\section{The measures: SSHR and SAHR}

The measures SSHR and SAHR are both able to predict reliability changes. The SSHR is applicable to track sections between stations, whereas the SAHR can be used for a station, or for all arrivals from a certain track at that station.

Although a large decrease in the SSHR or in the SAHR leads to a large decrease in delays in most cases, it is hard to predict the exact size of the delay reduction. Using a weighted average of the two measures may be advantageous, because it takes heterogeneity into account, and it weighs the arrival headways more heavily than the departure delays.

\section{Equalizing headways}

Minimizing the SSHR or the SAHR implies equalizing the headways. Although a reduction in these measures indicates a reduction in delays, minimizing the sum of SSHRs or SAHRs over the network is not necessarily optimal. This can for example be seen from the SSHR in the practical case, where a large reduction on one section 
(Rtd-Gd) has much less influence on the reliability than a small reduction of the SSHR on another track (Gd-Gvc).

\section{Utilize and Build}

Benutten en Bouwen (Utilize and Build) is the vision and the intended direction of the combined Dutch railway branch for the future, up to 2020. Experts from the ministry of Traffic and Waterworks, the railway infrastructure manager ProRail, the passenger operator Netherlands Railways, and the cargo operator Railion (Nederlandse Spoorwegen et al., 2003) have participated in this project. The main problem is how to facilitate the ever expanding railway traffic on the limited infrastructure. The starting point of the project is to better utilize the existing infrastructure, which is made feasible by means of small but smart infrastructure investments.

Homogenization of the railway system is one of the basic elements of Benutten en Bouwen. Although the main focus is on a limited homogenization where intercity trains stop at a few more stations of medium large size, full homogenization is also discussed and not excluded as a solution.

\section{Other consequences of homogenization}

Although reliability will increase when train services are homogenized, there are several other important characteristics to be considered both for passengers and operators. Homogenization can have its influence on many of those characteristics.

- Travel time for passengers is an important determinant of service quality in case of homogenization. The planned travel time may decrease for some passengers, but increase for others. The number of passenger transfers and the transfer times may also change. This requires a further mobility analysis, which falls outside the scope of this paper.

- Infrastructural needs can possibly change due to other train lengths, but also due to other locations for overtakings, and due to another way of coordinating trains at large transfer stations.

- When the timetable is homogenized, the rolling stock can be standardized as well. The total required number of rolling stock units can also change.

- Homogenization by one large operator may lead to additional time-slots in the timetable, which might be assigned to other operators. Evidently this would, in the end, lead to an increased SSHR and SAHR. Therefore, network wide cooperation is necessary for a beneficial introduction of a homogenized timetable.

- Besides timetabling, the rolling stock and crew schedules can also have a considerable influence on delay propagation.

\section{Conclusions}

In this paper the Sum of Shortest Headway Reciprocals (SSHR) and Sum of Arrival Headway Reciprocals (SAHR) were described. These measures are used for evaluating the heterogeneity of the timetable and for the prediction of the reliability. The SSHR can be applied to a whole section and has the desirable property that it decreases both when trains are spread better over the hour and when railway traffic is more homogeneous. The SAHR also has the property of decreasing when the trains are spread better over the hour. It lacks a direct link to the heterogeneity, but takes it into account implicitly. 
The presented cases show a large reliability increase for homogenized services, which supports the hypothesis that we stated in section 3: the heterogeneity resulting from the line plan and the timetable has a negative influence on the punctuality and the reliability of a railway system.

In other words, when the SSHR and SAHR show large decreases, then there are usually also large decreases in delay propagation. Therefore, a relatively simple rule of thumb for timetable design is to minimize the SSHR and the SAHR. This may improve the reliability of the offered services.

Although homogenization may lead to a sizable increase in punctuality of the offered railway services, homogenization may also effect other features of the railway product, both for passengers and for operators and infrastructure managers. When homogenizing train services, these other consequences should also be considered. This is a subject for further research. The relationship between the consequences for the different operators and the infrastructure managers also stresses the importance of cooperation between these parties.

\section{References}

R. Bergmark, 1996. Railroad capacity and traffic analysis using SIMON. In Computers in Railways V, 183-191. WIT Press.

M. Carey, 1998. Optimizing scheduled times, allowing for behavioral response. Transportation Research Part B, 32(5), 329-342.

M. Carey, 1999. Ex ante heuristic measures of schedule reliability. Transportation Research Part B, 33(7), 473-494.

M. Carey and A. Kwiecinski, 1995. Properties of expected costs and performance measures in stochastic models of scheduled transport. European Journal of Operational Research, 83, 182-199.

A.F. De Kort, 2000. Advanced railway planning using (max,+) algebra. In Computers in Railways VII, 257-266. WIT Press.

H. Fischer, M. Bolemant, A. Margaritov and G.-R. Friedrich, 1995. Das Projekt SABINE - Simulation und Auswertung des Betriebsablaufs im Netz. In Simulation und Simulatoren für den Schienenverkehr, 451-462, VDI-Verlag. In German.

R.M.P. Goverde, G. Hooghiemstra and H.P. Lopuhaä, 2001. Statistical Analysis of Train Traffic; The Eindhoven Case. Delft University Press, Delft, the Netherlands.

R.M.P. Goverde and M.A. Odijk, 2002. Performance evaluation of network timetables using PETER, in: Computers in Railways VIII, WIT Press, Southampton. 
R.M.P. Goverde and G. Soto y Koelemeijer, 2000. Performance evaluation of periodic railway timetables: theory and algorithms. Delft University Press, Delft, the Netherlands.

I.A. Hansen, 2000. Station capacity and stability of train operations. In Computers in Railways VII, 809-816. WIT Press.

A. Higgins and E. Kozan, 1998. Modeling train delays in urban networks. Transportation Science, 32(4), 346-357.

A. Higgins, E. Kozan and L. Ferreira, 1995. Modeling delay risks associated with train schedules. Transportation Planning and Technology, 18, 89-108.

J.S. Hooghiemstra, 1994. An automatic timetable generator for the Dutch railway network, in Computers in Railways IV, Vol 2, Computational Mechanics Publications, Southampton, pp. 109-116.

T. Huisman, R.J. Boucherie and N.M. van Dijk, 2002. A solvable queueing network model for railway networks and its validation and applications for the Netherlands. European Journal of Operational Research, 142, 30-51.

T. Huisman and R.J. Boucherie, 2001. Running times on railway sections with heterogeneous train traffic. Transportation Research Part B, 35, 271-292.

D. Hürlimann, 2001. Objektorientierte Modellierung von Infrastrukturelementen und Betriebsvorgängen im Eisenbahnwesen (Object oriented modeling of infrastructure elements and business processes in railways). PhD. thesis, ETH Zürich, Switzerland. In German.

A.H. Kaas, 2000. Punctuality model for railways. In Computers in Railways VII, 809816. WIT Press.

H. König, 2001. VirtuOS, Simulieren von Bahnbetrieb. Betrieb und Verkehr, 50(1-2), 44-47. In German.

D. Middelkoop and M. Bouwman, 2000. Train network simulator for support of network wide planning of infrastructure and timetables. In Computer in Railways VII, 267-276. WIT Press.

D. Middelkoop and M. Bouwman, 2001. SIMONE: large scale train network simulations. In Proceedings of the 2001 Winter Simulation Conference, 1042-1047, 2001. Institute of Electrical and Electronic Engineers, Piscataway, New Jersey.

Nederlandse Spoorwegen, 2002. Spoorboekje (Timetable), 15 december $2002 \mathrm{t} / \mathrm{m} 13$ december 2003. Nederlandse Spoorwegen, the Netherlands. In Dutch.

Nederlandse Spoorwegen, ProRail, Railion and ministerie van Verkeer en Waterstaat, 2003. Benutten en Bouwen, het plan van de spoorsector (Utilize and Build, the plan of the railway branch). The Netherlands. In Dutch. 
A. Schaafsma, 2001. Dynamisch railverkeersmanagement (Dynamic rail traffic management). PhD. thesis, Technical University Delft, Delft, the Netherlands. In Dutch.

G. Soto y Koelemeijer, A.R. Iounoussov, R.M.P. Goverde and R.J. Van Egmond, 2000. PETER, a performance evaluator for railway timetables. In Computers in Railways VII, 405-414. WIT Press.

Subiono, 2000. On classes of min-max-plus systems and their applications. $\mathrm{PhD}$. thesis, Technical University Delft, Delft, the Netherlands.

R.J. Van Egmond, 2000. An algebraic approach for scheduling train movements. In Proceedings CASPT 2000, Berlin, Germany.

M. Wahlborg, 1996. Simulation models: important aids for Banverket's planning process. In Computers in Railways V, 1, 175-181, Computational Mechanics Publications, Southampton, United Kingdom. 


\section{Publications in the Report Series Research* in Management}

ERIM Research Program: "Business Processes, Logistics and Information Systems"

2003

Project Selection Directed By Intellectual Capital Scorecards

Hennie Daniels and Bram de Jonge

ERS-2003-001-LIS

http://hdl.handle.net/1765/265

Combining expert knowledge and databases for risk management

Hennie Daniels and Han van Dissel

ERS-2003-002-LIS

http://hdl.handle.net/1765/266

Recursive Approximation of the High Dimensional max Function

Ş. II. Birbil, S.-C. Fang, J.B.G. Frenk and S. Zhang

ERS-2003-003-LIS

http://hdl.handle.net/1765/267

Auctioning Bulk Mobile Messages

S.Meij, L-F.Pau, E.van Heck

ERS-2003-006-LIS

http://hdl.handle.net/1765/274

Induction of Ordinal Decision Trees: An MCDA Approach

Jan C. Bioch, Viara Popova

ERS-2003-008-LIS

http://hdl.handle.net/1765/271

A New Dantzig-Wolfe Reformulation And Branch-And-Price Algorithm For The Capacitated Lot Sizing Problem With Set Up Times

Zeger Degraeve, Raf Jans

ERS-2003-010-LIS

http://hdl.handle.net/1765/275

Reverse Logistics - a review of case studies

Marisa P. de Brito, Rommert Dekker, Simme D.P. Flapper

ERS-2003-012-LIS

http://hdl.handle.net/1765/277

Product Return Handling: decision-making and quantitative support

Marisa P. de Brito, M. (René) B. M. de Koster

ERS-2003-013-LIS

http://hdl.handle.net/1765/278

\footnotetext{
A complete overview of the ERIM Report Series Research in Management: $\underline{\text { http://www.erim.eur.nl }}$

ERIM Research Programs:

LIS Business Processes, Logistics and Information Systems

ORG Organizing for Performance

MKT Marketing

F\&A Finance and Accounting

STR Strategy and Entrepreneurship
} 
Managing Product Returns: The Role of Forecasting

Beril Toktay, Erwin A. van der Laan, Marisa P. de Brito

ERS-2003-023-LIS

http://hdl.handle.net/1765/316

Improved Lower Bounds For The Capacitated Lot Sizing Problem With Set Up Times

Zeger Degraeve, Raf Jans

ERS-2003-026-LIS

http://hdl.handle.net/1765/326

In Chains? Automotive Suppliers and Their Product Development Activities

Fredrik von Corswant, Finn Wynstra, Martin Wetzels

ERS-2003-027-LIS

http://hdl.handle.net/1765/363

Mathematical models for planning support

Leo G. Kroon, Rob A. Zuidwijk

ERS-2003-032-LIS

http://hdl.handle.net/1765/332

How and why communications industry suppliers get "squeezed out" now, and the next phase

L-F Pau

ERS-2003-033-LIS

http://hdl.handle.net/1765/317

Financial Markets Analysis by Probabilistic Fuzzy Modelling

Jan van den Berg, Uzay Kaymak, Willem-Max van den Bergh

ERS-2003-036-LIS

http://hdl.handle.net/1765/323

WLAN Hot Spot services for the automotive and oil industries :a business analysis or : "Refuel the car with petrol and information , both ways at the gas station "

L-F Pau, M.H.P.Oremus

ERS-2003-039-LIS

http://hdl.handle.net/1765/318

A Lotting Method for Electronic Reverse Auctions

U. Kaymak, J.P. Verkade and H.A.B. te Braake

ERS-2003-042-LIS

http://hdl.handle.net/1765/337

Supply Chain Optimisation in Animal Husbandry

J.M. Bloemhof, C.M. Smeets, J.A.E.E. van Nunen

ERS-2003-043-LIS

http://hdl.handle.net/1765/353

A Framework for Reverse Logistics

Marisa P. de Brito and Rommert Dekker

ERS-2003-045-LIS

http://hdl.handle.net/1765/354

An assessment system for rating scientific journals in the field of ergonomics and human factors Jan Dul and Waldemar Karwowski

ERS-2003-048-LIS

http://hdl.handle.net/1765/432 
Circulation of Railway Rolling Stock: A Branch-and-Price Approach

Marc Peeters and Leo Kroon

ERS-2003-055-LIS

http://hdl.handle.net/1765/902

Emerging Multiple Issue e-Auctions

Jeffrey E. Teich, Hannele Wallenius, Jyrki Wallenius and Otto R. Koppius

ERS-2003-058-LIS

http://hdl.handle.net/1765/922

Inventory Management with product returns: the value of information

Marisa P. de Brito and E. A. van der Laan

ERS-2003-060-LIS

http://hdl.handle.net/1765/925

Promising Areas for Future Research on Reverse Logistics: an exploratory study

Marisa P. de Brito

ERS-2003-061-LIS

http://hdl.handle.net/1765/926

A Polynomial Time Algorithm for a Deterministis Joint Pricing and Inventory Model

Wilco van den Heuvel and Albert P.M. Wagelmans

ERS-2003-065-LIS

http://hdl.handle.net/1765/929

A geometric algorithm to solve the ni/g/ni/nd capacitated lot-sizing problem in o(t²) time

Wilco van den Heuvel and Albert P.M. Wagelmans

ERS-2003-066-LIS

http://hdl.handle.net/1765/930

Arrival Processes for Vessels in a Port Simulation

Eelco van Asperen, Rommert Dekker, Mark Polman, Henk de Swaan Arons \& Ludo Waltman

ERS-2003-067-LIS

http://hdl.handle.net/1765/973

The distribution-free newsboy problem with resalable returns

Julien Mostard, Rene de Koster and Ruud Teunter

ERS-2003-068-LIS

http://hdl.handle.net/1765/975

A note on a multi-period profit maximizing model for retail supply chain management

Wilco van den Heuvel and Albert P.M. Wagelmans

ERS-2003-072-LIS

http://hdl.handle.net/1765/991

The Impact of Complexity, Rate of Change and Information Availability on the Production Planning and Control Structure: Evidence from Medium-Sized Dutch Discrete Manufacturing Firms

Marcel van Assen and Steef van de Velde

ERS-2003-083-LIS

http://hdl.handle.net/1765/1033

The impact of innovation and organizational factors on APS adoption: Evidence from the Dutch discrete parts industry

Bart van Hezewijk, Marcel van Assen and Steef van de Velde

ERS-2003-084-LIS

http://hdl.handle.net/1765/1067 
Equilibrium Constrained Optimization Problems

S. Birbil, G. Bouza , J.B.G. Frenk and G. Still

ERS-2003-085-LIS

http://hdl.handle.net/1765/1068

Network-Based Business Process Management: Embedding Business Logic In Communications Networks L-F Pau and P.H.M.Vervest

ERS-2003-086-LIS

http://hdl.handle.net/1765/1070 